ORIGINAL ARTICLE

\title{
The relative efficacy of two brief treatments for sleep problems in young learning disabled (mentally retarded) children: a randomised controlled trial
}

\author{
P Montgomery, G Stores, L Wiggs
}

Arch Dis Child 2004;89:125-130. doi: 10.1136/adc.2002.017202

See end of article for authors' affiliations

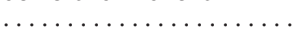

Correspondence to: Dr P Montgomery, University of Oxford Section of Child and Adolescent Psychiatry, Park Hospital, Headington, Oxford OX3 7LQ, UK; paul.montgomery@ psych.ox.ac.uk

Accepted 12 March 2003
Background: Settling and night waking problems are particularly prevalent, persistent, and generally considered difficult to treat in children with a learning disability, although intervention trials are few. Scarce resources, however, limit access to proven behavioural treatments.

Aims: To investigate the efficacy of a media based brief behavioural treatment of sleep problems in such children by comparing (1) face-to-face delivered treatment versus control and (2) booklet delivered treatment versus controls.

Methods: The parents of 66 severely learning disabled children aged 2-8 years with settling and/or night waking problems took part in a randomised controlled trial with a wait-list control group. Behavioural treatments were presented either conventionally face-to-face or by means of a 14 page easy to read illustrated booklet. A composite sleep disturbance score was derived from sleep diaries kept by parents. Results: Both forms of treatment were almost equally effective compared with controls. Two thirds of children who were taking over 30 minutes to settle five or more times per week and waking at night for over 30 minutes four or more times per week improved on average to having such settling or night waking problems for only a few minutes or only once or twice per week $(H=34.174, d f=2, p<0.001)$. These improvements were maintained after six months.

Conclusions: Booklet delivered behavioural treatments for sleep problems were as effective as face-to-face treatment for most children in this population.
D ifficulty going to sleep and repeated distressed waking in the night are the most common sleep problems reported in severely learning disabled children, even into the teenage years. ${ }^{1}$ Prevalence rates of severe sleep disorders in this population have been assessed as $86 \%$ up to age $6,81 \%$ in $6-11$ year olds, and $77 \%$ in $12-16$ year olds. ${ }^{2}$ They are associated with learning and behaviour problems, high levels of maternal stress, serious parenting difficulties (including physical punishment and even child abuse), and marital discord. ${ }^{3}{ }^{4}$

Despite their serious nature and consequences, help with these sleep problems is poorly provided. ${ }^{5}$ Medication is usually ineffective, can cause unwelcome side effects, and is generally not favoured by parents. In contrast, behavioural treatments aimed at teaching the child new sleep behaviours can be very effective, even in long standing severe cases. ${ }^{6}$ These types of treatment are described in detail in France and Hudson (1993). ${ }^{7}$ While the individual efficacy of the treatment components is not fully known, their cumulative effect appears to be good. ${ }^{8}$ Their successful use has been linked to improvements in child behaviour, maternal health, and family functioning. ${ }^{10}$ Unfortunately, the behavioural approach is under-utilised, possibly because in traditional form, this treatment requires considerable time and effort from health professionals.

The results of a Cochrane Collaboration systematic review ${ }^{11}$ suggested that the use of media based materials, such as booklets and videotapes, in presenting child behaviour management strategies might be worthwhile at a primary care level. In view of the personal, social, health, and (to the nation) economic benefits of successful and early treatment of these sleep disorders, it is highly desirable to devise effective behavioural treatments which require less time and professional expertise for use in primary care. ${ }^{12}$ An evaluation of such a treatment was the aim of this study.
The aim was to compare face-to-face delivered treatment (versus control) with booklet delivered treatment (versus control). The study was not powered to detect a difference between the two active forms of treatment.

The hypotheses were:

- Booklet delivered behavioural treatment for sleep problems in learning disabled children would be as effective as face-to-face delivery versus control

- Effects of the treatments, however delivered, would last for six months

- The control group would not improve while waiting for treatment

- The parents would evaluate the booklet positively.

\section{METHODS}

\section{Participants}

The study involved children aged 2-8 years with any form of severe learning disability, confirmed by the general practitioner (GP). Severe sleep problems were defined according to standardised criteria ${ }^{13}$ as follows: (1) night waking occurring three or more times a week for more than a few minutes and the child disturbing the parents or going into their room or bed; and/or (2) settling problems occurring three or more times a week with the child taking more than one hour to settle and disturbing the parents during this time. These problems needed to have been present for at least three months and not be explicable in terms of a physical problem such as pain.

\section{Intervention}

This consisted of the same instructions to parents in one of two randomly allocated formats: 
- Using a brief booklet

- Conventionally, face-to-face.

In both cases the approach was entirely behavioural and focused on the child's sleep problems and the parents' response to them, covering the following topics:

- Normal sleep: setting realistic expectations, indicating the advantages to the whole family when children sleep well.

- Introduction to behavioural techniques in general: how behaviours can be triggered by events that precede them, and encouraged (or discouraged) by providing appropriate reinforcement; management strategies such as ignoring, consistency, and reward systems.

- Monitoring behaviour: using a sleep diary to record settling, wakings, daytime naps, sleepiness, etc; and using this information to devise and monitor treatment plans.

- Good sleep habits: for example, sleep as a learned behaviour, appropriate surroundings, removal of daytime naps, importance of clear routines, putting children down to sleep while awake but drowsy, removal of bottles, how to deal with possible physical causes of sleep disturbance such as wet nappies or being too hot/cold.

- Specific techniques for changing undesirable behaviour:

- Settling and nightwaking: (i) ignoring the child; (ii) checking briefly on the child at increasingly extending intervals with minimal attention; (iii) gradually decreasing the physical contact between child and parent during the episode.

- Sleeping in the parents' bed: (i) raising awareness of the problem; (ii) returning the child to bed as needed using the settling techniques above.

- Rewards for encouraging desirable behaviour.

The intervention was delivered by one of the researchers (PM) either conventionally face-to-face, or briefly via booklet at the second meeting (see Procedure). With the face-to-face approach, time spent with the parent was about 90 minutes and followed precisely the same material as in the booklet. This information was based, with permission, on a booklet written by the Child Psychology Department, Dudley Road Hospital, West Birmingham and expanded by the authors to address the needs of learning disabled children. It consisted of 14 pages of text with cartoons to make the booklet more appealing and illustrate some of the techniques. Written information for parents available in most bookshops and primary care centres contains similar information. There is little variation in the content of these kinds of materials, although none has previously been systematically tested and validated.

The booklet was evaluated using the Flesch Readability Test, ${ }^{14}$ a standard method of assessing the level of secondary education required to understand written material. The Flesch index was 74.3 and the Flesch-Kincaid Grade level 7.3 , indicating that it is readable by someone educated up to age 13. For comparison, it is simpler than three quarters of UK newspapers.

\section{Assessments}

\section{Sleep}

A brief sleep problem screening questionnaire, previously shown to be valid and reliable, ${ }^{13}{ }^{15}$ was used to identify children whose parents reported a severe sleep problem as set out in table 1, and to establish whether this was likely to respond to a behavioural intervention or whether it might reflect a physical problem such as pain. A sleep history was taken in a semi-structured interview. ${ }^{16}$ Parents were given a sleep diary to complete for the two weeks prior to each

\begin{tabular}{|c|c|c|}
\hline Problem & Score & Criteria \\
\hline Settling frequency & $\begin{array}{l}0 \\
1 \\
2\end{array}$ & $\begin{array}{l}1 \text { or } 2 \text { times per week } \\
3 \text { or } 4 \text { times per week } \\
5 \text { or more times per week }\end{array}$ \\
\hline Settling duration & $\begin{array}{l}0 \\
1 \\
2\end{array}$ & $\begin{array}{l}\text { Few minutes } \\
\text { Up to and including } 30 \text { minutes } \\
\text { Over } 30 \text { minutes }\end{array}$ \\
\hline Night waking frequency & $\begin{array}{l}0 \\
1 \\
2\end{array}$ & $\begin{array}{l}0 \text { or } 1 \text { times per week } \\
2 \text { or } 3 \text { times per week } \\
4 \text { or more times per week }\end{array}$ \\
\hline Night waking duration & $\begin{array}{l}0 \\
1 \\
2\end{array}$ & $\begin{array}{l}\text { Few minutes } \\
\text { Up to and including } 30 \text { minutes } \\
\text { Over } 30 \text { minutes }\end{array}$ \\
\hline
\end{tabular}

assessment, primarily to record the times of sleep onset, offset, and night waking, but also to describe how they dealt with the problems. From the diary a Composite Sleep Disturbance Score was calculated by summing the score on each problem.

The minimum entry score was 4 , representing, for example, a child with settling problems lasting more than 30 minutes at least five times weekly. The maximum is 8 , indicating a child who also wakes in the night for at least 30 minutes more than three nights each week. Since parental report is the main way in which child sleep problems come to light in primary care, the Composite Sleep Disturbance Score was chosen as the primary outcome measure.

\section{Parental evaluation of response}

Parents were asked what minimum improvement in their child's sleep would be needed for them to consider the intervention worthwhile, following Jones and Verduyn (1983). ${ }^{17}$ Fifty five parents $(83 \%)$ said that if the problem reduced by half they would think the intervention worthwhile, so a reduction in the Composite Sleep Disturbance Score of $50 \%$ or more was taken as the secondary outcome measure.

\section{Evaluation of the booklet}

Participants in the booklet groups were given a brief questionnaire to evaluate it in terms of relevance, ease with which the booklet was understood, and usefulness. Each item could be scored from 0 to 4 ("not at all..." "quite...." "not very..." "not at all ...."). The range of scores was, therefore, 0 (worst) to 12 (best).

\section{Design}

This was a randomised controlled trial with two active treatment groups, conventional and booklet delivery of behavioural advice, as well as a crossover control group. Power calculations based on previous work with conventionally delivered behavioural treatment ${ }^{6}$ showing a reduction in the treatment group's Composite Sleep Disturbance Scores from 6.73 to 2.96 (SD 2.24) and in controls from 7.23 to 6.29 (SD 2.70), indicated that group sizes of 20 would give $95 \%$ power at the 0.05 level of significance. As the relative difference of effect between the two delivery methods was unknown, a pragmatic decision was taken to recruit as many participants as possible in the time available.

\section{Procedure}

Screening questionnaires and letters requesting details of their child's sleep (without the offer of treatment) were sent to the parents of all 268 children attending the special schools or receiving pre-school teacher counsellor services in 
Oxfordshire, Berkshire, and Buckinghamshire. Parents of eligible children were sent a letter inviting them to participate in the treatment trial and informed consent was obtained at this point from parents and from the child's GP. Those agreeing were given a baseline assessment of the sleep questionnaire and subjective measurement of their child's sleep using a sleep diary kept for two weeks before each assessment. A detailed sleep history was taken to assess other clinical features of the children's sleep.

Participants were then randomly allocated to one of the experimental groups.

- Brief treatment (booklet): giving parents a simple booklet, describing appropriate techniques for dealing with various sleep problems.

- Conventional treatment: seeing parents in their homes and presenting face-to-face the behavioural strategies used in the booklet to address their child's sleep problem.

- Crossover control group: no intervention for six weeks, at which point they were re-randomised into an active treatment group.

The family received a second visit (on average five days later) and delivery of the appropriate intervention. No contact was then made until six weeks later, when a sleep diary was sent and all measures were repeated in participants' homes. Total contact time with each family was approximately $180 \mathrm{~min}$ utes for face-to-face conventional treatment (of which approximately 90 minutes was spent on the intervention) and 90 minutes with the booklet group for assessments.

All participants received a postal follow up in which parents completed a sleep diary for one week, approximately six months post-intervention. From this the Composite Sleep Disturbance Score was again calculated to assess whether any treatment effects had been maintained. Families failing to return this questionnaire were reminded once by mail and then telephoned for collection of these data.

\section{Allocation}

Seventy five opaque envelopes were produced for the initial randomisation and lodged with an independent staff member. Each contained a slip of paper with the word "conventional", "booklet", or "control" (25 each). The randomisation was performed by this staff member selecting an envelope for each participant immediately after the initial assessment meeting with parents. For the re-randomisation of the control crossover group this process was repeated with a second batch of 26 envelopes, half each with the word "conventional" or "booklet". The researcher conducting the study was therefore blind to the nature of the treatment allocated until after the post-treatment assessment. Following that point both participant and researcher were aware of the treatment group to which they had been randomised.

\section{Analyses}

Distributions of the data were not normal, even after transformation, so all analyses presented here are nonparametric. The main comparisons were across three groups (conventional face-to-face treatment, booklet treatment and control). Post hoc multiple comparisons were performed to identify which groups differed.

Care was taken to ensure that treatment content for the conventional group was consistent with the booklet. Taped sessions were compared with the booklet and a selection of these were rated by an experienced clinical psychologist who helped to ensure consistency between the two delivery methods. A selection of Composite Sleep Disturbance Scores was randomly cross checked for consistency by an independent rater who found agreement levels greater than $95 \%$.

\section{RESULTS}

Of 268 parents approached, 184 (69\%) replied to the invitation letter and screening questionnaire. Of these, 102 $(55 \%)$ were invited to join the study as their children met criteria; 76 responded and actually joined the study, and 66 (42 boys and 24 girls), completed it as shown in fig 1 .

The groups did not differ significantly on any baseline sociodemographic or medical measures (see table 2). Children were aged between 27 and 101 months. Four children were said to have epilepsy. Thirty of the parents left school before the age of 18, and 36 left aged 19 or older.

\section{Composite sleep disturbance scores \\ Baseline}

Table 3 shows the Composite Sleep Disturbance Scores by group at baseline. Statistically there was no significant difference between them (Kruskal Wallis test statistic $(\mathrm{H})=0.362, \mathrm{df}=2, \mathrm{p}=0.834)$, although sleep problems appeared slightly worse in the group receiving conventional treatment, which may be clinically important. A difference of 1 point on this scale would suggest night waking for up to 30 minutes rather than for a few minutes (see table 1).

\section{Post-treatment}

Significant group differences were found in Composite Sleep Disturbance Scores over time $(\mathrm{H}=34.174, \mathrm{df}=2, \mathrm{p}<0.001)$, as shown in table 3, but the effects of active treatment were very similar, irrespective of delivery method. Post-hoc multiple comparisons using Bonferroni correction for type 1 errors $^{18}$ confirmed that the significant differences were between the active treatments and controls. Power calculations indicated that it was not possible to detect a difference between the two active treatments, as a sample of 6325 would be required to achieve $95 \%$ power. A replication phase after the controls received treatment was not possible as there were no controls remaining with whom to compare them.

\section{Six month follow up}

One-week sleep diaries were obtained from 64 of the 66 participating families in order to assess the durability of any treatment effects six months after the children began active treatment. As shown in table 3, the data indicated that treatment effects had been maintained.

\section{Controls}

No significant improvements in sleep scores were observed during the control phase. However, when treatment was delivered, by whichever method, they made similar improvements to those seen in groups who received treatment immediately.

\section{Response to treatment}

In addition to the primary outcome measure, the parental evaluation of response as defined by a 50\% symptom reduction was also considered. The conventionally treated group included 15 "responders" versus 5 "non-responders". Comparable figures were 15 versus 7 for the booklet group, and 0 versus 24 for controls. These data support the hypothesis that booklet delivered and therapist delivered treatments were equally effective when compared with controls $(\mathrm{H}=36.975$, $\mathrm{df}=2, \mathrm{p}<0.001)$. In the control-crossover groups similar results were obtained when they received active treatment, with 9 responders versus 3 non-responders in the conventional group and 8 versus 4 in the booklet group. 


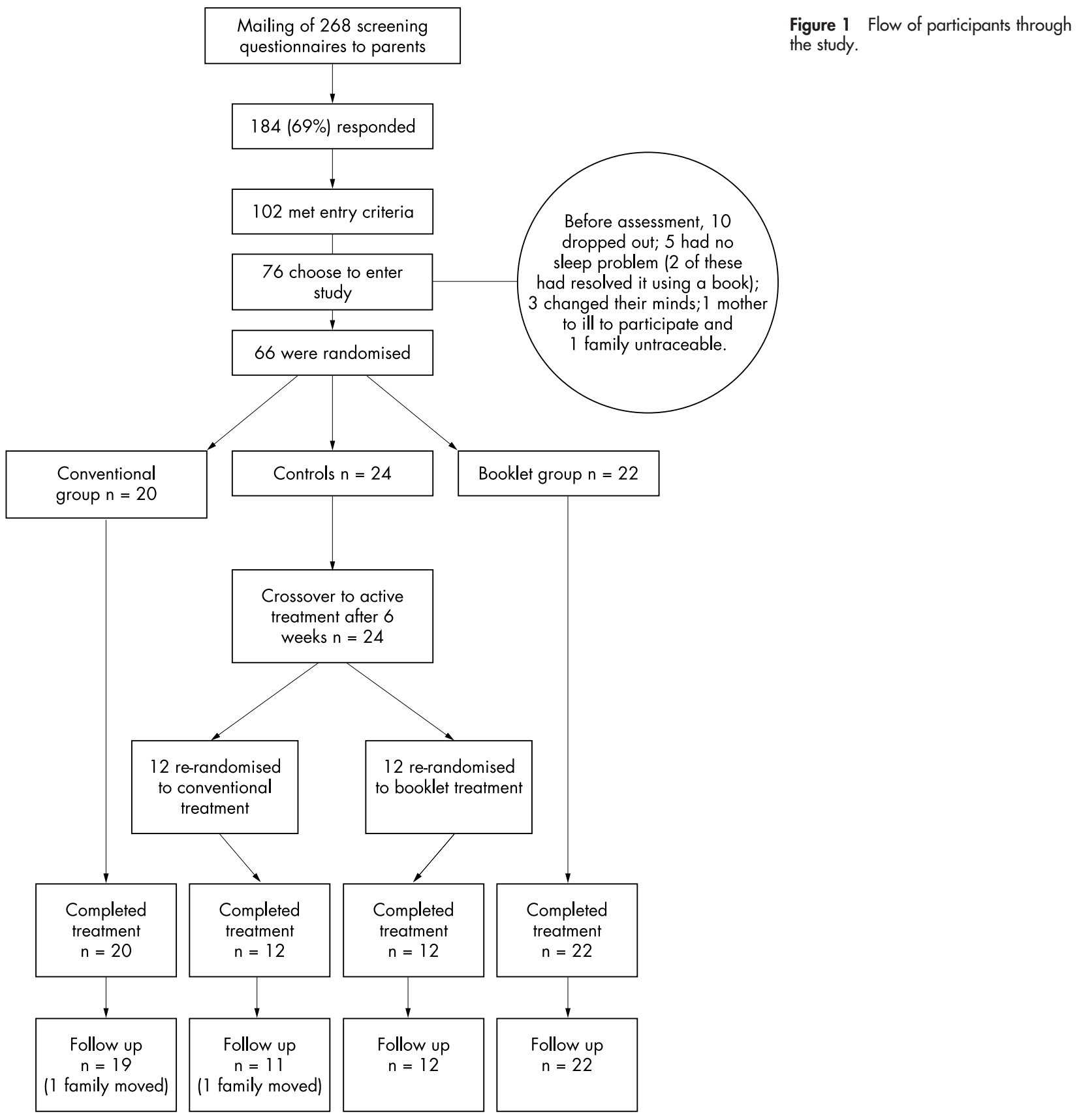

\section{Evaluation of the booklet}

All participants who received the booklet (whether immediately or after a period in the control group) were asked to evaluate it briefly in terms of relevance, ease with which it was understood, and usefulness. Twenty three replied (68\%). The mean score was 10.17 (SD 1.87) $(\max =12)$, indicating that parents found the booklet appropriate and helpful. In 13 cases both parents reported that they used it, in nine it was the mother only, and in one case the father only.

\section{Sociodemographic factors}

No social indicators such as family structure or social class were found to relate to outcome with respect to the Composite Sleep Disturbance Score change (for example, number of parents, Fisher exact test statistic $(S)=8.51$, $\mathrm{p}<0.8$; number of siblings, $\mathrm{S}=41.62, \mathrm{p}<0.4$; social class,
$\mathrm{S}=26.80, \mathrm{p}<0.9)$. However, to predict which families are likely to have success with the booklet would require a much larger sample size. ${ }^{19}$ There were no families for whom literacy was a problem, even though more than a third of the parents left school at age 16 or younger. The importance of ethnic group could not be considered as only eight of the 66 families described themselves as non-Caucasian. Small group sizes prevented statistical analysis of the importance of health, medication, and epilepsy status. However, these possible factors appeared to be similar across groups.

\section{DISCUSSION}

This study confirms the effectiveness of conventional behavioural treatment for sleep problems in children with learning disabilities (as reported by parents), and shows that brief delivery of this treatment using a booklet did not reduce 
Table 2 Baseline demographic data of the children and their families

\begin{tabular}{|c|c|c|c|c|c|c|c|c|}
\hline & \multicolumn{2}{|c|}{ Total sample } & \multicolumn{2}{|l|}{ Therapist } & \multicolumn{2}{|l|}{ Booklet } & \multicolumn{2}{|l|}{ Controls } \\
\hline & Frequency & $\%$ & Frequency & $\%$ & Frequency & $\%$ & Frequency & $\%$ \\
\hline \multicolumn{9}{|l|}{ Conditions } \\
\hline Autism & 21 & 31.8 & 7 & 35 & 4 & 18.2 & 10 & 41.7 \\
\hline Down's syndrome & 8 & 12.1 & 3 & 15 & 3 & 13.6 & 2 & 8.3 \\
\hline Global dev delay & 5 & 7.6 & 2 & 10 & 1 & 4.5 & 2 & 8.3 \\
\hline Epilepsy & 4 & 6.1 & 1 & 5 & 1 & 45 & 2 & 8.3 \\
\hline Other* & 14 & 21.1 & 4 & 20 & 4 & 19.5 & 6 & 15.1 \\
\hline No diagnosis & 18 & 27.3 & 4 & 20 & 10 & 45.5 & 4 & 16.7 \\
\hline \multicolumn{9}{|l|}{ Class } \\
\hline Professional & 24 & 36.4 & 8 & 40 & 6 & 27.3 & 10 & 41.7 \\
\hline Manag/technical & 16 & 24.2 & 4 & 20 & 6 & 27.3 & 6 & 25.0 \\
\hline Skilled manual & 9 & 13.6 & 3 & 15 & 3 & 13.6 & 3 & 12.5 \\
\hline Skilled non-manual & 8 & 12.1 & 1 & 5 & 4 & 18.2 & 3 & 12.5 \\
\hline Unskilled & 9 & 13.6 & 4 & 20 & 3 & 13.6 & 2 & 8.3 \\
\hline \multicolumn{9}{|l|}{ No. of parents } \\
\hline 1 & 11 & 17.5 & 5 & 25 & 1 & 4.5 & 5 & 21 \\
\hline 2 & 54 & 82 & 15 & 75 & 20 & 91 & 19 & 79 \\
\hline 3 & 1 & 1.5 & 0 & 0 & 1 & 4.5 & 0 & 0 \\
\hline
\end{tabular}

its effect. Treatment benefits were maintained at six months. Previous research in both this kind of population and normal children has shown that the behavioural techniques used here can contribute to the successful management of serious sleep problems. The importance of this study, however, lies in its demonstration that this sort of treatment, which is often hard to access owing to resource constraints, may be presented briefly via a booklet with no loss of effectiveness.

The non-parametric tests used here are, arguably, less powerful than parametric tests, but a convincing treatment effect was still found. Using the parent generated index of satisfaction (sleep problems improving by $50 \%$ or more), $75 \%$ of the conventional group and $68 \%$ of the booklet group were satisfied. The minimal differences between the two delivery methods suggest that, clinically, the booklet has a good therapeutic effect and parents rated it highly. It is short, easy to read, well illustrated, and makes specific reference to the needs of learning disabled children, which is rare in the selfhelp field.

In addition to the interventions themselves, other factors could affect efficacy. Motivation is often thought to affect success of cognitive behavioural treatments. ${ }^{20}$ These families may have been highly motivated, having responded to the screening letter. However, this did not offer treatment, but simply asked for details of their child's sleep problem. The amount and nature of face-to-face contact during assessment meetings (common to both treatment groups) may be an issue, ${ }^{21}$ and further research into the importance of therapist contact in media based therapies is planned.

While there may, of course, be limitations to media based therapies, it may be that in some ways, these forms of treatment could even be more helpful than conventional ones. For example, it might be more easily followed equally

Table 3 Composite Sleep Disturbance Score (CSDS) over time by treatment group

\begin{tabular}{lllll}
\hline Group & $\mathbf{n}$ & $\begin{array}{l}\text { Baseline } \\
\text { Mean (SD) }\end{array}$ & $\begin{array}{l}\text { Post-treatment } \\
\text { Mean (SD) }\end{array}$ & $\begin{array}{l}\text { Follow up }(6 \mathrm{mth}) \\
\text { Mean (SD) }\end{array}$ \\
\hline $\begin{array}{l}\text { Conventional } \\
\text { treatment }\end{array}$ & 20 & $6.55(1.31)$ & $2.4(1.93)$ & $1.89(2.02)$ \\
$\begin{array}{l}\text { Brief treatment } \\
\text { Controls }\end{array}$ & 22 & $6.18(1.46)$ & $2.55(2.76)$ & $2.08(2.89)$ \\
All participants & 66 & $6.10(2.35)$ & $5.75(1.54)$ & \\
\hline
\end{tabular}

by both parents and other carers, so that the handling of the child is more consistent. In this trial, only five cases in the conventional group had both parents present, whereas more than half the parents who evaluated the booklet reported that both of them used it. The booklet might also empower parents to modify the treatment to suit their individual situations in a way that conventional methods may not. ${ }^{22}$

Individual differences and low numbers deserve consideration when dealing with a heterogeneous sample such as this one. However, the differences in the primary outcome measure between each of the active treatments and controls are sufficiently large to show that each treatment is effective compared to no treatment. As discussed earlier, a very large sample size would be required to detect any statistically significant difference between conventional and brief treatment. In view of the constraints on healthcare resources, this distinction may not be a pressing issue.

The characteristics of those families in whom treatment effects were disappointing are of interest. This study did not aim to assess predictors of success with these treatments. However, in conventional delivery of this sort of treatment, the communication skills of the child, quality of the parental relationship, and emotional resources in the family are thought to be important factors in success. ${ }^{23}$ Literacy levels might also be considered important, but this was not borne out by the current findings. Another study, involving sleep disordered clinic patients with limited literacy skills found very minor differences between video and booklet for improving knowledge, and concluded that simple written information was effective. ${ }^{24}$

These results are consistent with other work on media based treatments in general. ${ }^{7}$ A major reason for interest in such treatments is that they have important cost implications. Potential savings include not only direct costs in terms of reduced therapist time, but also indirect costs, because sleep problems in this population often contribute to other medical problems, such as hyperactivity, and to negative effects on parents' mental and physical health. ${ }^{12}{ }^{25}$ Increasing demands on healthcare providers in most countries mean that service provision can be inadequate to meet these needs. This work supports the conclusions of studies addressing other aspects of child health ${ }^{21}{ }^{26}$ in showing that media based interventions have considerable potential to improve productivity in clinical practice. 


\section{ACKNOWLEDGEMENTS}

The authors would like to thank the children and families who participated in this research, the NHS Research and Development Board for funding it, Christina Crawford for the artwork in the booklet, and Judith Ponsford for her work on the randomisation.

\section{Authors' affiliations}

P Montgomery, G Stores, L Wiggs, University of Oxford Section of Child and Adolescent Psychiatry, Oxford, UK

\section{REFERENCES}

1 Wiggs L, Stores G. Severe sleep disturbance and daytime challenging behaviour in children with severe learning disabilities. J Intellect Disabil Res 1996;40:518-28.

2 Bartlett LB, Rooney V, Spedding S. Nocturnal difficulties in a population of mentally handicapped children. Br J Ment Subnorm 1985:31:54-9.

3 Chavin W, Tinson S. The developing child: children with sleep difficulties. Health Visitor 1980;53:477-80.

4 Quine L. Severity of sleep problems in children with severe learning difficulties: description and correlates. J Community Appl Soc Psychol 1992;2:247-68.

5 Wiggs L, Stores $G$. Sleep problems in children with severe intellectual disabilities: what help is being provided? J Appl Res Intellect Disabil 1996:9:160-5.

6 Wiggs L, Stores G. Behavioural treatment for sleep problems in children with severe learning disabilities and challenging daytime behaviour: effect on sleep patterns of mother and child. J Sleep Res 1998;7:119-26.

7 France KG, Hudson S-M. Management of infant sleep disturbance: a review. Clin Psychol Rev 1993;13:635-47.

8 France KG, Hudson SM. Behavior management of infant sleep disturbance. J Appl Behav Anal 1990;23:91-8.

9 Ramchandani $\mathbf{P}$, Wiggs $L$, Webb $V$, et al. A systematic review of treatments for settling problems and night waking in young children. BMJ 2000;320:209-13.
10 Quine L. Helping parents to manage children's sleep disturbance. In: Gibbons J, Dept of Health., eds. The Children Act 1989 and family support: principles into practice. London: HMSO, 1992.

11 Montgomery P. Media-based behavioural treatments for behavioural disorders in children. Cochrane Database Syst Rev 2001;2:CD002206.

12 Morris S, James-Roberts IS, Sleep J, et al. Economic evaluation of strategies for managing crying and sleeping problems. Arch Dis Child 2001;84:15-19.

13 Richman N, Graham PJ. A behavioural screening questionnaire for use with 3-year-old children: preliminary findings. J Child Psychol Psychiatry $1971 ; 12: 5-33$.

14 Flesch R. A new readability yardstick. J Appl Psychol 1948;32:221-33.

15 Simonds JF, Parraga H. Prevalence of sleep disorders and sleep behaviors in children and adolescents. J Am Acad Child Psychiatry 1982;21:383-8.

16 Stores G. A clinical guide to sleep disorders in children and adolescents. Cambridge: Cambridge University Press, 2001.

17 Jones DP, Verduyn CM. Behavioural management of sleep problems. Arch Dis Child 1983;58:442-4.

18 Altman DG. Practical statistics for medical research. Boca Raton, FL: Chapman \& Hall/CRC, 1999

19 Concato J, Peduzzi P, Holford TR, et al. Importance of events per independent variable in proportional hazards analysis. Background, goals, and general strategy. J Epidemiol Community Health 1995;48:1495-501.

20 Keiisers GPJ, Schaap CPDR, Hoogduin CAL, et al. Preliminary results of a new instrument to assess patient motivation for treatment in cognitive-behaviour therapy. Behav Cogn Psychother 1999;27:165-79.

21 Gould RA, Clum GA. A meta-analysis of self-help treatment approaches. Clin Psychol Rev 1993;13:169-86.

22 Montgomery P, Cook C. Parents, education and family centres. In: WarrenAdamson C, ed. Family centres and their international role in social action: social work as informal education. London: Ashgate, 2001.

23 Quine L. Sleep problems in children with mental handicap. J Ment Defic Res 1991;35:269-90.

24 Murphy PW, Chesson AL, Walker L, et al. Comparing the effectiveness of video and written material for improving knowledge among sleep disorders clinic patients with limited literacy skills. South Med J 2000;93:297-304.

25 Hossain JL, Shapiro CM. The prevalence, cost implications, and management of sleep disorders: an overview. Sleep Breath 2002;6:85-102.

26 Marrs RW. A meta-analysis of bibliotherapy studies. Am J Community Psychol 1995;23:843-70. 